tumor was removed with Stereotactic Radiosurgery (Gamma Knife system).

Conclusions Unilateral hearing loss in a child is a reason for an extended examination in order to exclude retrocochlear pathology.

\section{HYPERKINETIC AND HYPOKINETIC MOVEMENT DISORDERS - IN PEDIATRIC CLINICAL PRACTICE}

N Barišic ${ }^{*}$, I Lehman, B Bunoza, D Chudy, V Duranović, B Jernej, U Ahting, T Haack, H Prokisch, M Willemsen. Department of Pediatrics, Clinical Medical centre Zagreb, University of Zagreb Medical School, Zagreb, Croatia

10.1136/archdischild-2021-europaediatrics.408

To present heterogenous group of motor movement disorders of different etiology and clinical features.

Medical history and clinical exam and assessment, MR neuroimaging, metabolic tests, molecular genetics, lumbar puncture and cerebrospinal fluid exam, antibodies to surface neuronal antigens, EEG monitoring, abdominal ultrasound were performed.

Patients with autosomal dominant torsion dystonia DYT 6 (THAP1 gene mutation) and movement disorders caused by mutations in ATP1A3, SCN8A, CaCNa1, PANK2, POLG1 genes and acquired disorders: autoimmune (NMDAR) encephalitis, dyskinetic cerebral palsy, opsoclonus myoclonus ataxia will be presented as well as treatment response.

MD can manifest alone or as part of complex phenotypes of different etiology. Considerable overlap of MD and seizures exists especially in patients with epileptic encephalopathies, ataxias and spasticity in whom clinical diagnosis can be more challenging.

\section{HEART OR BRAIN GENETICS?-ICTAL CARDIORESPIRATORY ARREST DURING THE FIRST AFEBRILE EPILEPTIC SEIZURE WITH LEFT TEMPORAL ONSET- LIFE THREATENING EVENT WITH GOOD OUTCOME}

Nina Barišić. Department of Pediatrics, Clinical Medical centre Zagreb, University of Zagreb Medical School, Zagreb

\subsection{6/archdischild-2021-europaediatrics.409}

Temporal lobe has important role in the regulation of autonomic function, while the insular cortex is associated with cardiac autonomic functions control. Focal epileptic activity in the temporal lobe may cause cardiac dysfunction.

Patient and Methods A girl at the age of 12 developed cardiorespiratory arrest after she vomited several times during night. She was resuscitated and mechanically ventilated. Her pro-BNP and troponin values were increased, as well as CK, ECG monitoring in ICU was unremarkable, however HolterECG showed ST elevation and prolonged QRS complex. Her EEG monitoring showed focal dyscharges from frontotemporal region right. Heart US showed mild dilatation of apical region. Cardioverter defibrillator (ICD) was implanted and carbamazepine treatment was introduced. Her brain MR was normal as well as her heart US after 5 days. She manifested febrile seizures during childhood, attention deficit hyperactivity disorder and joint laxity. Next generation sequencing revealed heterozygous KCND3 gene mutation :c.916G>A;p.Gly306Ser. KCND3 is reported for Brugada syndrome as well associated with developmental delay, intelectual disability, ataxia, epilepsy and attention deficit hyperactivity disorder.

Conclusion Ictal discharges involving limbic structures may be a cause of both apnoea and ictal asystolia by inhibition of brainstem cardiorespiratory control circuits caused by the mutation in KCND3 gene.

Cardiorespiratory arrest may occur as results of autonomic dysfunction provoked probably by postictal suppression.

\section{Paediatric Pulmonology}

\section{INFLAMMATORY LUNG DISEASE IN RETT SYNDROME}

Sanela Šalig*, Ana Tripalo Batoš, Jasna Čepin Bogović, Vlasta Đuranović, Oleg Jadrešin, Ivan Pavić. Varaždin County Health Center/Children's Hospital Zagreb

\subsection{6/archdischild-2021-europaediatrics.410}

Rett syndrome is a progressive pervasive neurodevelopmental disorder that affects female patients and is the second most common cause of mental retardation in the female gender, with an incidence of $1: 10,000$ to $1: 15,000$ live born girls. The classic form of Rett syndrome in $95 \%$ of cases is caused by de-novo mutation on the X-chromosome-linked gene encoding the methyl-CpG-binding protein 2 . It is characterized by mental retardation, ataxia, epilepsy, characteristic stereotyped movements of the hands and loss of their normal function and breathing disorders. There is no effective cure, but early recognition of the disease and early treatment, primarily antiepileptic and respiratory, can delay the onset of further complications. Breathing disorders, including apnea, hyperventilation, rapid and shallow breathing, breath holding and spontaneous Valsalva maneuvers, are due to ventilatory perfusion inequality and are the result of a number of factors, including oxidative stress and chronic subclinical inflammation. The aim of this case report is to present a girl with Rett syndrome who has been treated with antibiotics on several occasions for radiologically persistent changes in the right upper pulmonary lobe as the changes are understood as pneumonic infiltrate. A girl aged 3 years and 2 months diagnosed with Rett syndrome was hospitalized for additional diagnostic treatment of radiologically verified persistent changes of the upper right pulmonary lobe. The girl was treated with antibiotics at the ages of 15, 17 and 18 months as to have had bacterial pneumonia of the right upper pulmonary lobe. In July 2019, esophagogastroduodenoscopy, bronchoscopy, and computed tomography of the thorax were performed. Computed tomography showing in the region of the upper pulmonary lobe the consolidation of the pulmonary parenchyma with visible air bronchogram and deformation of the bronchi in the branches oriented toward the medial and in the basal segments of the upper paracardial lobe. The described changes are within the framework of Rett syndrome and correspond to the contents filled the alveoli with impaired ventilation and the minimal segment deformation of the bronchi by type of bronchiectasis. Changes of the upper right pulmonary lobe, on computed tomography of the thorax, are found in 50\% of children with Rett syndrome and are chronic in nature and do not require antibiotic treatment. 